\title{
Aplikasi Markerless Augmented Reality Dewata Nawa Sanga Berbasis Android
}

\author{
I Wayan Andis Indrawan, I Putu Agung Bayupati, Desy Purnami Singgih Putri \\ Program Studi Teknologi Informasi Universitas Udayana \\ Bukit Jimbaran, Bali, Indonesia, telp. (0361) 701806 \\ e-mail : andisindrawan@gmail.com, bayuhelix@yahoo.com, desysinggihputri@gmail.com
}

\begin{abstract}
Abstrak
Kebudayaan Agama Hindu di Bali merupakan suatu kultur yang sangat dilestarikan dan dijaga oleh masyarakat Hindu di Bali agar tetap adiluhung. Dewata Nawa Sanga merupakan salah satu Konsep Agama Hindu yang dianut oleh masyarakat Hindu di Bali. Dewata Nawa Sanga memiliki makna sembilan Dewa sebagai manifestasi Tuhan yang bertugas menjaga dan menguasai sembilan arah mata angin. Aplikasi Augmented Reality Dewata Nawa Sanga dikembangkan bertujuan untuk meningkatkan pengetahuan masyarakat Agama Hindu di Bali mengenai konsep dari Dewata Nawa Sanga, melalui suatu media pembelajaran mengingat pentingnya Dewata Nawa Sanga bagi umat Hindu di Bali. Aplikasi Augmented Reality Dewata Nawa Sanga dikembangkan menggunakan metode markerless, jadi user cukup melakukan rotasi pada perangkat Android untuk melihat posisi Dewa di sembilan arah mata angin serta mengetahui informasi dari masing-masing dewa tersebut. Aplikasi Augmented Reality Dewata Nawa Sanga memberikan edukasi tentang unsur-unsur detail mengenai setiap Dewa di sembilan arah mata angin melalui fitur Information View dalam bentuk narasi. Aplikasi yang dihasilkan secara tidak langsung mengedukasi pengguna untuk mengetahui arah mata angin yang dikuasai dan dijaga oleh sembilan dewa sebagai manifestasi dari tuhan melalui tampilan Augmented Reality dengan menggunakan sensor giroskop.
\end{abstract}

Kata Kunci: Dewata Nawa Sanga, Augmented Reality, Android, Markerless, Budaya

\begin{abstract}
The culture of Hinduism in Bali is very preserved and maintained by the Hindus in Bali to remain dignified. Dewata Nawa Sanga is one of the Hindu Religion Concept embraced by the Hindus in Bali. Dewata Nawa Sanga means nine deities as a manifestation of God in charge of guarding and controlling the nine wind direction. The application of Augmented Reality Dewata Nawa Sanga developed to increase the knowledge of Hindus in Bali about the concept of Dewata Nawa Sanga, through a learning medium considering the importance of Dewata Nawa Sanga for Hindus in Bali. The application of Augmented Reality Dewata Nawa Sanga developed using the markerless method, so users simply rotate the Android devices to see the position of Deity in the nine wind directions and to know the information of each of the deities. Application of Augmented Reality Dewata Nawa Sanga provides education about detail elements about each Deity in nine wind direction through Information View feature in narrative form. The resulting application indirectly educates the user to know the direction of the controlled and guarded by nine Deity as a manifestation of the god through Augmented Reality display by using gyroscope sensors.
\end{abstract}

Keywords: Dewata Nawa Sanga, Augmented Reality, Android, Markerless, Culture

\section{Pendahuluan}

Kebudayaan Agama Hindu di Bali merupakan kultur yang sangat dilestarikan dan dijaga oleh masyarakat Hindu di Bali agar tetap adiluhung [1]. Dewata Nawa Sanga merupakan salah satu Kebudayaan Agama Hindu yang dianut oleh masyarakat Hindu di Bali [2], yang memiliki makna sembilan Dewa sebagai manifestasi Tuhan yang bertugas menjaga dan menguasai sembilan arah mata angin. Sembilan Dewa tersebut antara lain Dewa Wisnu, Dewa Sangkara, Dewa Iswara, Dewa Sambhu, Dewa Mahadewa, Dewa Brahma, Dewa Maheswara, Dewa Rudra dan Dewa Siwa. Sembilan Dewa tersebut masing-masing memiliki sakti (istri), wahana (kendaraan), sanjata (senjata) serta unsur-unsur lainnya. 
Penelitian sebelumnya yang dilakukan oleh Made Aditya Setiadiartha di jurnal "Game Edukasi Dewata Nawa Sanga Berbasis Android" tahun 2015 [3], menjelaskan Aplikasi Game Edukasi Dewata Nawa Sanga merupakan aplikasi Android yang menyediakan pembelajaran tentang Dewata Nawa Sanga dan bagian-bagiannya. Game edukasi Dewata Nawa Sanga dibuat dengan tujuan untuk menarik minat belajar pengguna, juga mengenalkan tentang Dewata Nawa Sanga dan bagian-bagiannya karena dikemas dalam bentuk permainan.

Aplikasi Augmented Reality Dewata Nawa Sanga merupakan pengembangan dari penelitian sebelumnya yaitu Game Edukasi Dewata Nawa Sanga yang dikemas menggunakan teknologi Augmented Reality. Penelitian ini dirancang terdiri dari 2 fitur utama yaitu tampilan AR View dan tampilan Information View. AR View merupakan fitur yang mensimulasikan user berada di titik tengah dalam tampilan Augmented Reality sehingga dapat melihat sembilan arah mata angin yang dijaga oleh sembilan Dewa virtual dalam bentuk 3 dimensi. User cukup melakukan rotasi menggunakan perangkat smartphone untuk melihat para Dewa tersebut. Fitur kedua yaitu Information View, yaitu tampilan informasi detail dari masing-masing Dewa. Fitur Information View menyediakan tampilan 3 dimensi dari Dewa, sakti, wahana, sanjata serta informasi 2 dimensi unsur-unsur lain secara lengkap yang dapat mengedukasi user untuk memahami dan mendalami pengetahuan tentang Dewata Nawa Sanga.

Penelitian dengan judul "Aplikasi Markerless Augmented Reality Dewata Nawa Sanga berbasis Android" dikembangkan menggunakan metode markerless dan berbasis Android. Markerless adalah metode yang digunakan untuk melacak objek dalam tampilan realitas tanpa penanda khusus. Metode markerless bergantung pada pelacakan fitur berbasis gambar, benda, koordinat dan GPS yang kemudian dijadikan target untuk dideteksi sehingga menampilkan benda virtual pada smartphone Android seperti penelitian yang dilakukan oleh Ferliyanto Waruwu, berjudul Augmented Reality Mobile Application of Balinese Hindu Temples. Penelitian tersebut memanfaatkan gambar pura pada brosur sebagai target untuk memicu munculnya objek 3 dimensi dari pura tersebut [4].

\section{Metodologi}

Proses Rancang Bangun Aplikasi Markerless Augmented Reality Dewata Nawa Sanga berbasis Android dilakukan menggunakan alur penelitian DSRM (Design Science Research Method). Alur penelitian secara garis besar terbagi menjadi dua bagian yaitu gambaran umum aplikasi dan diagram use case. Gambaran umum aplikasi memiliki dua proses yaitu front-end dan back end. Proses front-end menjelaskan pembuatan aplikasi mulai dari tahap pemrograman, desain objek 3 dimensi dewa, dewi, wahana dan senjata hingga menggabungkan seluruh komponen menjadi satu aplikasi dengan format file APK (application package kit). Proses back-end adalah proses yang menjelaskan sistematis cara kerja aplikasi di dalam smartphone. Diagram use case menjelaskan interaksi pengguna terhadap elemenelemen yang ada di dalam aplikasi.



Gambar 1. Gambaran Umum Aplikasi 
Gambar 1 merupakan gambaran umum dari Aplikasi Markerless Augmented Reality Dewata Nawa Sanga berbasis Android. Gambaran umum lanjutan dari gambaran umum aplikasi keseluruhan adalah gambaran umum proses yang merupakan gambaran hasil yang diharapkan dari sebuah proses Rancang Bangun Aplikasi Markerless Augmented Reality Dewata Nawa Sanga berbasis Android dengan salah satu fungsi sebagai media edukasi serta pembelajaran bagi masyarakat Hindu di Bali.

\subsection{Diagram Use Case}

Diagram Use Case digunakan untuk memberikan gambaran requirement fungsional dari Rancang Bangun Aplikasi Markerless Augmented Reality Dewata Nawa Sanga berbasis Android, serta berguna untuk memperlihatkan bagaimana aplikasi digunakan olah user.

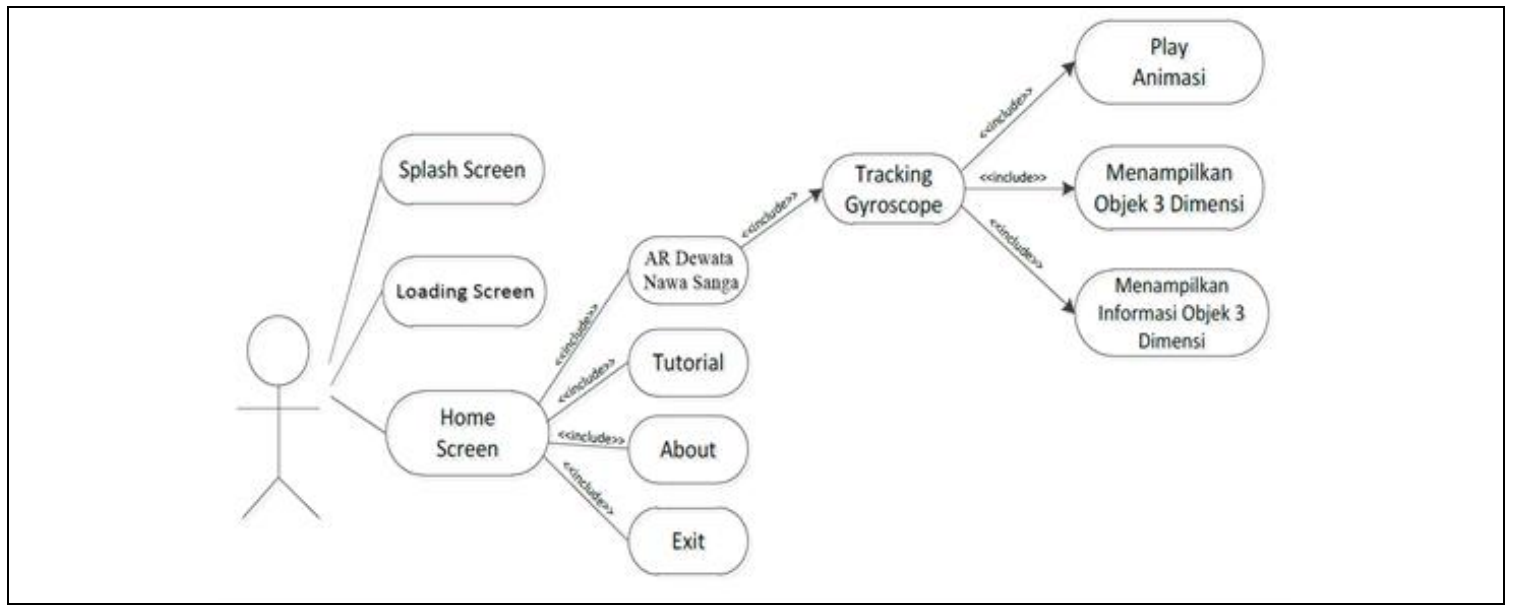

Gambar 2. Diagram Use Case

Gambar 2 menunjukan Diagram Use Case dari Aplikasi Augmented Reality Dewata Nawa Sanga. Diagram Use Case menggambarkan interaksi pengguna terhadap Aplikasi Augmented Reality Dewata Nawa Sanga dan antara elemen use case dengan elemen use case lainnya. Pengguna dapat menggunakan use case yang dirancang yaitu Menu AR Dewata Nawa Sanga, Menu Tutorial, Menu About dan Menu Exit sebagai sesuatu yang dapat dikerjakan. Pengguna dalam use case tersebut dapat memilih layanan tracking gyroscope yang merupakan layanan utama pada Aplikasi Augmented Reality Dewata Nawa Sanga. Model 3D, animasi dan informasi Dewata Nawa Sanga hanya dapat berjalan ketika proses tracking gyroscope telah dijalankan oleh sistem. Layanan tracking gyroscope merupakan sebuah layanan yang dapat digunakan oleh pengguna untuk melakukan tracking berupa rotasi 360 derajat sesuai gravitasi yang dilakukan oleh pengguna dengan keluaran model 3D, animasi dan informasi.

\section{Kajian Pustaka}

Bab kajian pustaka berisikan teori yang dapat digunakan sebagai penunjang dan yang menjadi dasar teori untuk pemecahan masalah dari penelitian yang dibuat.

\subsection{Dewata Nawa Sanga}

Dewata Nawa Sanga merupakan salah satu Konsep Agama Hindu yang dianut oleh masyarakat Hindu di Bali. Dewata Nawa Sanga memiliki makna sembilan Dewa sebagai manifestasi Tuhan yang bertugas menjaga dan menguasai sembilan arah mata angin. Sembilan Dewa tersebut antara lain Dewa Wisnu, Dewa Sangkara, Dewa Iswara, Dewa Sambhu, Dewa Mahadewa, Dewa Brahma, Dewa Maheswara, Dewa Rudra dan Dewa Siwa. Sembilan Dewa tersebut masing-masing memiliki Sakti (istri), Wahana (kendaraan), Sanjata (senjata), Bhuta, Aksara, Urip, Triwara, Caturwara, Pancawara, Sadwara, Saptawara, Astawara, Sangawara, Wuku, Sasih dan Bhuwana Alit serta unsur-unsur lainnya [2].

\subsection{Pengertian Augmented Reality}

Augmented Reality merupakan teknologi yang menggabungkan benda virtual dua dimensi ataupun tiga dimensi ke dalam sebuah dunia nyata lalu memproyeksikan objek-objek 
virtual tersebut dalam waktu nyata. Objek-objek virtual berfungsi menampilkan informasi yang tidak dapat diterima oleh manusia secara langsung. Hal ini membuat Augmented Reality berfungsi sebagai alat untuk membantu persepsi dan interaksi penggunanya dengan dunia nyata. Informasi yang ditampilkan oleh objek virtual membantu pengguna melaksanakan kegiatan-kegiatan dalam dunia nyata. Prinsip dasar dari Augmented Reality yaitu penggabungan dunia nyata dan virtual, berjalan secara interaktif dalam waktu nyata dan terdapat penggabungan antar benda dalam tiga dimensi yaitu benda maya terintegrasi dalam dunia nyata [5]. Kemampuan memunculkan objek 3D yang disertai dengan informasi pada perangkat smartphone membuat Augmented Reality tidak membosankan untuk digunakan. Augmented Reality bekerja berdasarkan pendeteksian citra yang berupa marker. Proses identifikasi marker berlangsung sampai aplikasi Augmented Reality menemukan kecocokan dengan marker yang telah ditentukan [6]. Augmented Reality memiliki dua metode untuk melakukan identifikasi marker, yaitu marker-based tracking dan markerless. Pelacakan berbasis marker atau marker-based tracking adalah teknik yang memberikan perintah ke komputer untuk melacak penanda yang telah dibuat dan ditempatkan pada posisi yang seharusnya. Metode markerless berbeda dengan pelacakan berbasis marker yang tidak memerlukan marker untuk menjadi pemicu tampilnya objek. Penelitian sebelumnya yang menggunakan metode markerless salah satunya dilakukan oleh Mas Aristamy yang berjudul Augmented Reality Bahasa Isyarat untuk Orang Tunarungu [7].

\subsection{Unity 3D}

Unity 3D merupakan sebuah game engine yang berbasis cross-platform. Aplikasi ini menggunakan bahasa $\mathrm{C \#}$ untuk melakukan programming. Editor pada Unity dibuat dengan user interface yang sederhana. Grafis pada unity dibuat dengan grafis untuk OpenGL dan directX. Unity mendukung semua format file, terutama format umum seperti semua format dari art applications [8]. Unity cocok dengan versi 64-bit dan dapat beroperasi pada Mac OS $\mathrm{x}$ dan Windows dan dapat menghasilkan game untuk Mac, Windows, Wii, iPhone, iPad dan Android. Unity secara rinci dapat digunakan untuk membuat game, real time animasi 3D dan visualisasi arsitektur dan isi serupa yang interaktif lainnya. Unity juga memiliki lisensi edukasi yang dapat digunakan oleh developer untuk media pembelajaran dalam mengembangkan aplikasi [9]. Aplikasi Unity 3D selain menjadi engine untuk membuat game juga sangat berperan dalam mengembangkan Aplikasi Augmented Reality. Aplikasi Augmented Reality sangat cocok untuk digunakan sebagai media pembelajalan seperti penelitian yang dilakukan oleh Wahya Diatmika dengan judul Augmented Reality Magic Book Pengenalan Binatang [10].

\subsection{Android}

Android adalah platform perangkat lunak dan sistem operasi untuk perangkat mobile berdasarkan kernel Linux dan dikembangkan oleh Google serta Open Handset Alliance. Hal ini memungkinkan pengembang untuk menulis kode yang dikelola dalam Bahasa Java, mengendalikan perangkat melalui Google yang mengembangkan Java library. Android tersedia sebagai sistem operasi open source. Android adalah kumpulan perangkat lunak open source yang dapat diunduh secara gratis untuk smartphone yang mencakup sistem operasi, middleware dan aplikasi utama berbasis Linux dan Java. Google membeli pengembang Android pada tahun 2005, dan Android diresmikan pada tahun 2007. Google merilis kode Android sebagai open source di bawah Lisensi Apache. Android memiliki banyak pengembang yang menciptakan aplikasi di seluruh dunia [11]. Penelitian yang dikembangkan menggunakan platform Android salah satunya dilakukan oleh Aditya Nugraha yang berjudul Augmented Reality Museum Bali Studi Kasus Gedung Karangasem dan Gedung Tabanan [12].

\section{Hasil dan Pembahasan}

Bab Hasil dan Pembahasan berisikan hasil dari penelitian yang dilakukan berupa Tampilan Augmented Reality Dewata Nawa Sanga. 


\subsection{Tampilan Aplikasi Augmented Reality Dewata Nawa Sanga}

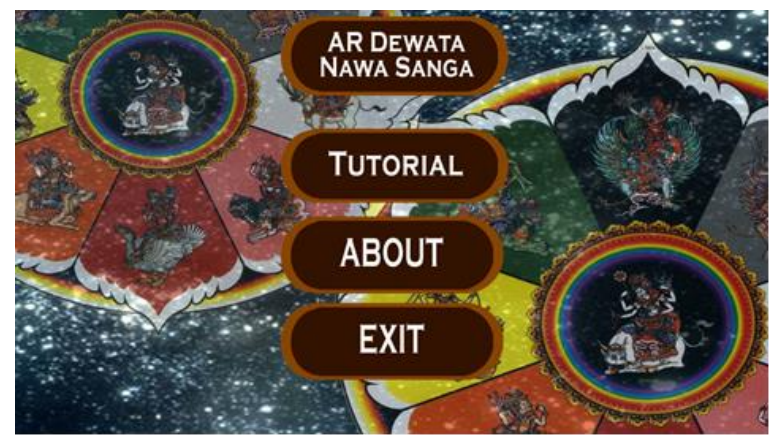

Gambar 3. Tampilan Home Screen

Gambar 3 merupakan Scene Home Screen yang menjadi interface awal pada saat membuka Aplikasi Augmented Reality Dewata Nawa Sanga. Scene Home Screen memiliki beberapa tombol yaitu Tombol AR Dewata Nawa Sanga, Tombol Tutorial, Tombol About dan Tombol Exit. Pengguna dapat memulai penggunaan aplikasi dengan memilih Tombol AR Dewata Nawa Sanga untuk melakukan tracking. Tombol Tutorial digunakan untuk memberikan informasi cara penggunaan aplikasi dan fitur-fitur yang ada pada Aplikasi Augmented Reality Dewata Nawa Sanga. Tombol About merupakan tombol untuk menampilkan informasi author atau perancang aplikasi. Tombol Exit untuk keluar dari Aplikasi Augmented Reality Dewata Nawa Sanga.

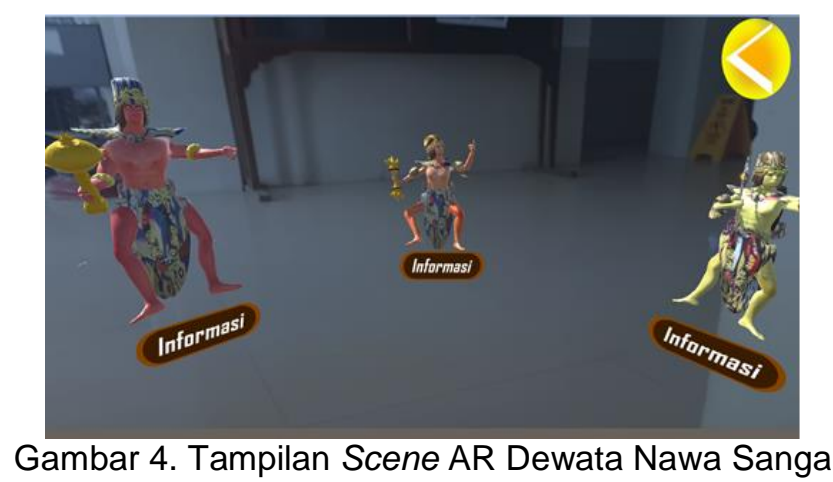

Gambar 4 ialah Scene AR Dewata Nawa Sanga yang berfungsi untuk memperlihatkan hasil dari penambahan objek virtual terhadap dunia nyata. Scene AR Dewata Nawa Sanga merupakan scene utama dari Aplikasi Augmented Reality Dewata Nawa Sanga dimana objek 3 dimensi, animasi dan informasi ditampilkan ketika kamera berotasi (tracking gyroscope). Scene AR Dewata Nawa Sanga bekerja menggunakan kamera dan sensor gyroscope untuk menampilkan objek 3 dimensi Dewata Nawa Sanga, animasi Dewata Nawa Sanga dan informasi Dewata Nawa Sanga pada smartphone Android.



Gambar 5. Tampilan Scene Information View 
Gambar 5 merupakan tampilan Menu Information View. Menu Information View adalah menu yang memberikan informasi detail dari dewa yang di-trigger dari menu AR View. Informasi yang ditampilkan dalam bentuk objek antara lain Dewa, Dewi, Senjata serta Wahana. Informasi lainnya dibuat dalam bentuk teks yang dikemas dengan latar berbentuk lontar yang mengedepankan kesan klasik.

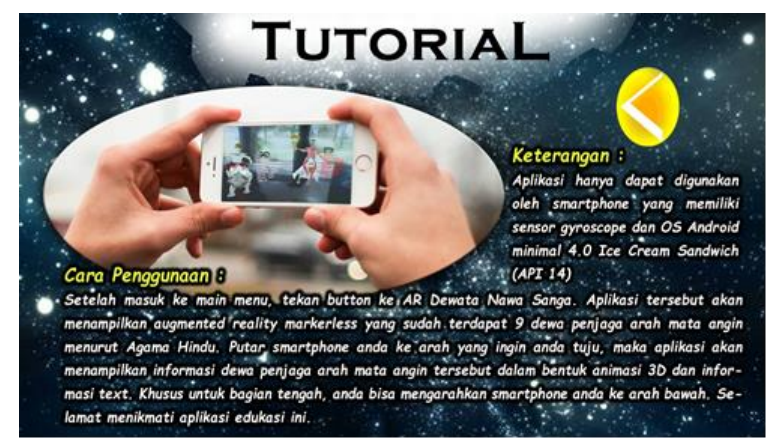

Gambar 6. Tampilan Scene Tutorial

Gambar 6 adalah Tampilan Scene Tutorial yang menampilkan informasi atau bantuan mengenai cara penggunaan dan fitur-fitur yang ada pada Aplikasi Augmented Reality Dewata Nawa Sanga. Scene Tutorial merupakan scene yang menjelaskan cara penggunaan Aplikasi Augmented Reality Dewata Nawa Sanga.

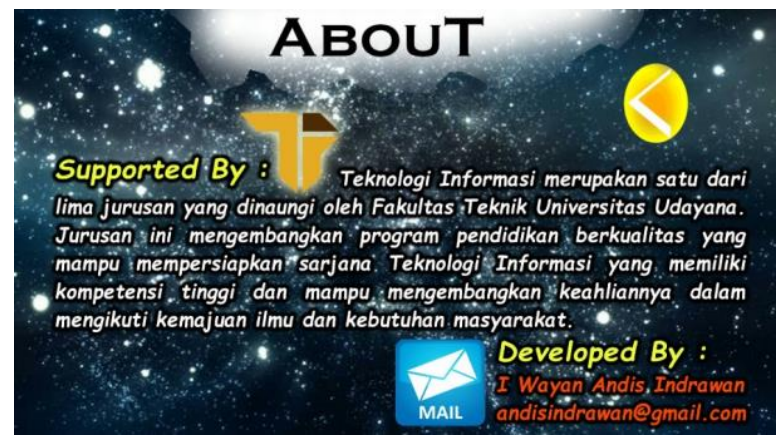

Gambar 7. Tampilan Scene About

Gambar 7 merupakan Tampilan Scene About yang menampilkan informasi developer Aplikasi Augmented Reality Dewata Nawa Sanga termasuk informasi deskripsi jurusan dan email yang terletak pada bagian bawah Tampilan Scene About.

\subsection{Penilaian Kuesioner}

Bab penilaian kuesioner berisikan hasil dari penilaian berupa kuesioner yang telah dilakukan terhadap beberapa responden.

\subsubsection{Analisis Sistem Aplikasi}

Metode pengambilan data yang digunakan untuk melakukan pengujian pada Aplikasi Augmented Reality Dewata Nawa Sanga adalah menggunakan metode survei, dimana pengambilan data dilakukan menggunakan kuesioner sebagai media survei. Survei melibatkan 30 responden yang terdiri dari masyarakat Hindu di Bali. 


\subsubsection{Aspek Kesesuaian Proses}

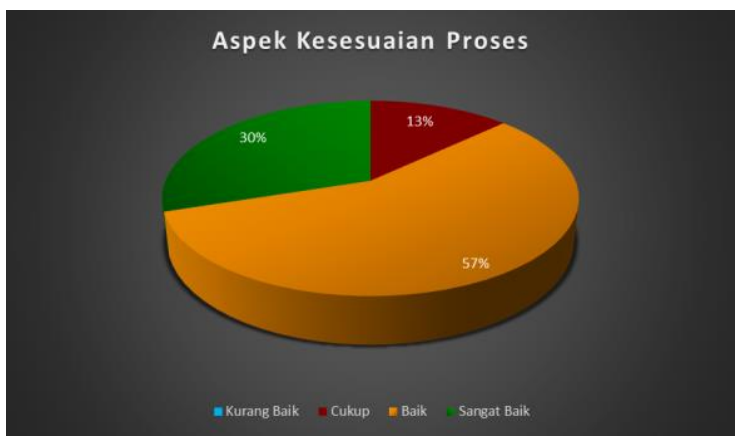

Gambar 8. Aspek Kesesuaian Proses

Gambar 8 merupakan diagram Aspek Kesesuaian Proses dari Aplikasi Augmented Reality Dewata Nawa Sanga. Aspek Kesesuaian Proses aplikasi memperoleh hasil tertinggi pada jawaban baik sebesar 57\%, jawaban cukup 13\% dan sangat baik $30 \%$. Berdasarkan persentase jawaban tersebut dapat diartikan bahwa seluruh proses yang terdapat dalam aplikasi berjalan sesuai fungsinya dengan baik.

\subsubsection{Aspek respon perpindahan $A R$ View ke Information View}

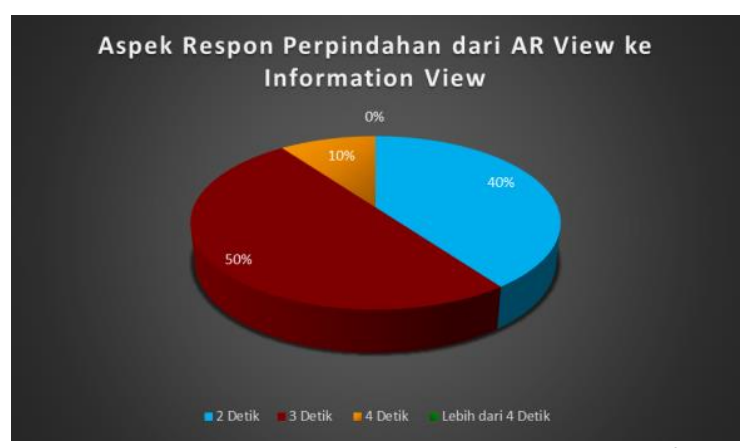

Gambar 9. Aspek respon perpindahan AR View ke Information View

Gambar 9 merupakan diagram Aspek Respon Perpindahan AR View ke Information View. Aspek Respon Perpindahan $A R$ View ke Information View merupakan pengujian lama waktu perpindahan $A R$ View ke Information View. Aspek Respon Perpindahan dari AR View ke Information View memperoleh hasil tertinggi pada jawaban 3 detik sebesar $50 \%, 40 \%$ pada jawaban 2 detik, $10 \%$ pada jawaban 4 detik, dan $0 \%$ pada jawaban lebih dari 4 detik. Berdasarkan persentase tersebut dapat diartikan bahwa proses perpindahan dari Scene $A R$ View ke Scene Information View sudah berjalan dengan baik dengan waktu rata-rata kurang dari 3 detik.

\subsubsection{Aspek User Interface}

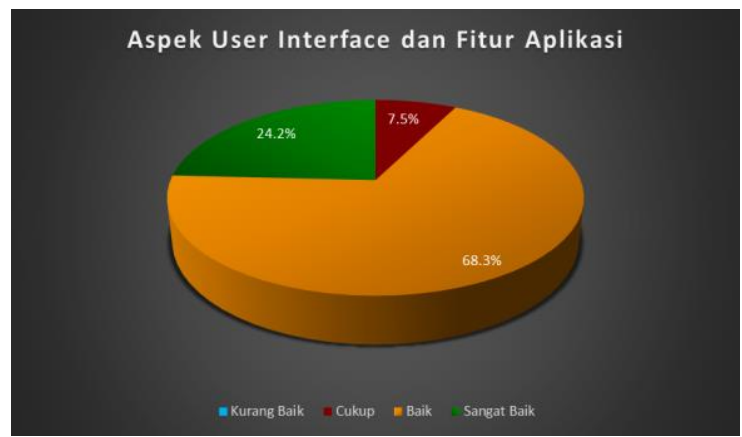

Gambar 10. Aspek User Interface

Aplikasi Markerless Augmented Reality Dewata Nawa Sanga Berbasis Android (I Wayan Andis Indrawan) 
Gambar 10 merupakan diagram Aspek User Interface. Aspek User Interface dan fitur merupakan pengujian tampilan aplikasi, fungsi tombol dan fitur yang terdapat pada aplikasi, kemudahan penggunaan aplikasi serta kemampuan perangkat menjalankan Aplikasi Augmented Reality Dewata Nawa Sanga. Aspek User Interface dan fitur aplikasi memperoleh hasil tertinggi pada jawaban baik sebesar $68.3 \%$, cukup $7.5 \%$ dan sangat baik dengan nilai $24.2 \%$. Berdasarkan persentase tersebut dapat diartikan bahwa Aplikasi Augmented Reality Dewata Nawa Sanga mudah dipahami dan mudah digunakan.

\section{Kesimpulan}

Kesimpulan yang dapat diambil dari Rancang Bangun Aplikasi Augmented Reality Dewata Nawa Sanga Berbasis Android adalah aplikasi yang dihasilkan mampu menampilkan sembilan Dewa yang merupakan bagian dari Dewata Nawa Sanga. Aplikasi ini seolah-olah mensimulasikan Dewa di setiap arah mata angin menggunakan sensor giroskop secara interaktif. Aplikasi ini juga menyediakan informasi secara lengkap mengenai unsur-unsur setiap Dewa dari Dewata Nawa Sanga melalui Fitur Information View dalam bentuk narasi. Hasil aplikasi ini tergolong sangat baik dan menarik, yang disajikan dengan total hasil survei yang telah dilakukan dimana hasilnya adalah $87 \%$ baik pada aspek kesesuaian proses. Berdasarkan tingkat usabilitas, Aplikasi Augmented Reality Dewata Nawa Sanga dapat digunakan dengan mudah dan dinikmati oleh semua kalangan terutama masyarakat Hindu di Bali, dibuktikan dengan hasil $92.5 \%$ baik pada aspek user interface. Hasil survei yang diperoleh membuktikan bahwa Aplikasi Augmented Reality Dewata Nawa Sanga dapat menjadi media pembelajaran serta sarana untuk mendalami konsep Agama Hindu khususnya Dewata Nawa Sanga, hal ini dapat dilihat dari hasil survei yang mendapat nilai baik pada semua aspek yang melebihi nilai $50 \%$.

\section{Daftar Pustaka}

[1] I. K. Suda, "Menyama Beraya sebagai Penjaga Solidaritas Sosial Kehidupan Krama Subak di Bali Tempo Dulu," Jurnal UNHI, vol. 2, p. 1, 2016.

[2] W. Yendra, Kanda Empat Dewa (Manusia Setengah Dewa Sakti Manderaguna). Surabaya: Paramita, 2010.

[3] M. Aditya Setiadiartha, I. N. Piarsa, and A. A. K. C. Wiranatha, "Game Edukasi Dewata Nawa Sanga Berbasis Android," Jurnal Merpati, vol. 3, no. 2252-3006, pp. 1-2, 2015.

[4] A. Ferliyanto Waruwu, I. P. Agung Bayupati, and I. K. G. Darma Putra, "Augmented Reality Mobile Application of Balinese Hindu Temples: DewataAR," International Journal Computer Network and Information Security, vol. 2, pp. 59-66, 2015.

[5] G. Yudha, P. Pangestu, N. Made, I. Marini, N. Kadek, and D. Rusjayanthi, "Aplikasi Web Augmented Reality Villa," Jurnal Merpati, vol. 5, no. 1, pp. 29-40, 2017.

[6] M. Lester, Professionel Augmented Reality Browsers for Smartphones. United Kingdom: Wiley Publishing, 2011.

[7] A. A. K. Oka Sudana, I. G. A. A. Mas Aristamy, and N. K. Ayu Wirdiani, "Augmented Reality Application of Sign Language for Deaf People in Android Based on Smartphone," International Journal Software Engineering Its Application, vol. 10, no. 8, p. 140, 2016.

[8] S. N. Adnin, I. Bagus, K. Widiartha, and I. M. B. Suksmadana, "Pembuatan Aplikasi Catalog 3D Desain Rumah Sebagai Sarana Promosi Dengan Menggunakan Unity 3D," Lontar Komputer, vol. 7, no. 1, pp. 676-687, 2016.

[9] A. Okita, Learning C\# Programming with Unity 3D. Broken Sound Parkway NW: Taylor \& Francis Group, LLC, 2015.

[10] I. D. G. Wahya Dhiyatmika, I. K. G. Darma Putra, and N. M. I. Marini Mandenni, "Aplikasi Augmented Reality Magic Book Pengenalan Binatang untuk Siswa TK," Lontar Komputer, vol. 6, no. 2, p. 121, 2016.

[11] P. S. Saurabh Bhardwaj, Priyanka Chouhan, Richa Sharma, "Android Operating Systems," International Journal of Engineering Technology and Management Research, vol. 1, no. 1, p. 1, 2013.

[12] I. G. Aditya Nugraha, I. K. G. Darma Putra, and I. M. Sukarsa, "Rancang Bangun Aplikasi Augmented Reality Museum Bali Berbasis Android Studi Kasus Gedung Karangasem dan Gedung Tabanan," Lontar Komputer, vol. 7, no. 2, pp. 93-103, 2016. 